Article

\title{
Smart City and Smart Tourism: A Case of Dubai
}

\author{
M. Sajid Khan ${ }^{1}$, Mina Woo ${ }^{2, *}$, Kichan Nam ${ }^{1}$ and Prakash K. Chathoth ${ }^{1}$ \\ 1 School of Business Administration, American University of Sharjah, Sharjah, UAE; \\ mskhan@aus.edu (M.S.K.); knam@aus.edu (K.N.); pkchathoth@aus.edu (P.K.C.) \\ 2 School of Business, Sogang University, Seoul 121-742, Korea \\ * Correspondence: drminawoo@gmail.com; Tel.: +82-10-9223-2080
}

Received: 31 October 2017; Accepted: 30 November 2017; Published: 8 December 2017

\begin{abstract}
Over the past decade, the advent of new technology has brought about the emergence of smart cities aiming to provide their stakeholders with technology-based solutions that are effective and efficient. Insofar as the objective of smart cities is to improve outcomes that are connected to people, systems and processes of businesses, government and other public- and private-sector entities, its main goal is to improve the quality of life of all residents. Accordingly, smart tourism has emerged over the past few years as a subset of the smart city concept, aiming to provide tourists with solutions that address specific travel related needs. Dubai is an emerging tourism destination that has implemented smart city and smart tourism platforms to engage various stakeholders. The objective of this study is to identify best practices related to Dubai's smart city and smart tourism. In so doing, Dubai's mission and vision along with key dimensions and pillars are identified in relation to the advancements in the literature while highlighting key resources and challenges. A Smart Tourism Dynamic Responsive System (STDRS) framework is proposed while suggesting how Dubai may able to enhance users' involvement and their overall experience.
\end{abstract}

Keywords: Dubai; smart city; smart tourism; destination image; data mining

\section{Introduction}

Smart systems, which enable the use and deployment of information to meet the needs of users, is emerging as a concept in the management of organizations, and macro systems as a whole. The "smart" concept, which essentially makes use of integrated systems and processes to find solutions, can be extended from a product/service at a micro level, to a city/nation at a macro level. As such, a smart city is "a community in which citizens, business firms, knowledge institutions, and municipal agencies collaborate with one another to achieve systems integration and efficiency, citizen engagement, and a continually improving quality of life" [1] (p. 92). In this regard, Neirotti et al. [2] defined a smart city as an ecosystem that is largely developed through the effective use of technology with the aim of improving the quality of life of citizens achieved through efficient integrated systems and services.

In the tourism context, smart destinations enable a city to achieve a unique selling proposition and to make the overall experience of tourists visiting the destination more fun-filled and convenient [3]. The literature highlights that the usage of data, control and coordination, and technology (protocols, processes, and infrastructures) have become precursors to the creation of better efficiencies, improved sustainability, economic development, and enhancement of quality of life for people living and working in the city [4]. More destinations are orienting towards the deployment of resources to build smart cities that include smart tourism as an integral component of the systems and processes. One such destination of interest from the Middle East context is Dubai.

Dubai is a major city in the Middle East and North Africa (MENA) region in terms of economic growth and development, which includes travel and tourism. Its growth over the past two decades, especially in terms of infrastructure, has made it a benchmark for not only developing countries, 
but also developed economies around the world. This rapid development has had an effect on tourism as seen in the recent growth in tourist arrivals. In 2016, the number of tourists to Dubai reached 14.87 million in an Emirate that has only 2.3 million residents/natives. In this regard, Dubai is ranked 4th after Bangkok (19.41 million), London (19.06 million), and Paris (15.45 million) [5-7]. The Government and other stakeholders in the Dubai context have recognized the strategic importance of tourism and its contribution to the economy while identifying it as a major economic sector along with trading, real estate and retail, among others.

The recent thrust to boost tourism in Dubai is projected to have a positive impact on tourist arrivals, which is estimated to reach 20 million by the year 2020 [8]. It is therefore important for Dubai to continue the allocation of key resources on an ongoing basis to emerging technologies in order to achieve the Emirate's growth objective. Clearly, smart city, of which smart tourism is a subset, is a medium for the accomplishment of the growth imperative for Dubai. Accordingly, Smart Dubai-Dubai's smart city initiative-has provided the impetus for the emergence and use of smart technologies for building a city of the future.

What is noteworthy in the Smart Dubai initiative is the use of the Happiness vision as the driving force that integrates stakeholders' well-being with the Emirate's strategic objectives. It is this alignment that has formed the basis for the development of the smart city concept in the context of Dubai. Consequently, smart solutions that range from online renewal of license, e-gate services at airports, integrated transportation systems, including M-parking and the like, are all aligned with the overall objective to serve key stakeholders and to create positive experiences.

Nonetheless, there are challenges that Dubai needs to address to fully transform to a smart city. These challenges emanate from its current resource structure and its readiness to align with the growth imperative identified previously. The alignment is of the essence that relates to people, systems and processes, which need to come together in delivering on the promise set forth in the Happiness vision. Using the existing literature, this paper proposes a strategic framework that addresses key challenges by integrating various systems and processes underlying Smart Dubai. For this purpose, first, we study the contemporary developments related to the smart city concept. A case study method is adopted based on secondary data of existing government reports, published research, books and articles, including Internet sources. Second, extending the concept of smart city to smart tourism, we explore the destination image of Dubai and evaluate it from a smart tourism destination perspective. Data mining technique is employed to analyze the perception of Dubai's destination image. Finally, this paper proposes a new framework of smart tourism, Smart Tourism Dynamic Responsive System (STDRS).

The structure of the paper is as follows. We first delve into smart cities and smart tourism in Section 2 while using the literature to identify their characteristics. We then provide an account of the Dubai Smart City initiative in Section 3 while identifying its pillars and dimensions that are the cornerstones of the concept. In Section 4, we identify the factors that form the basis for the emergence of Dubai as a smart tourism destination while discussing their significance and importance. We conclude with the identification of key gaps in Dubai's smart city and smart tourism initiative while proposing a framework that addresses them.

\section{Smart City and Smart Tourism}

\subsection{Smart Cities and Their Characteristics}

In essence, the term "smart city" is used to denote the business model used by a city as it relates to how specific goals are met using innovative systems and processes with a stakeholder orientation. At the heart of this lies managing innovation and change accomplished through technological solutions and collaborative processes that underlie the accomplishment of goals. The smart orientation does not necessarily need to be Information and Communications Technology (ICT) driven. The orientation towards "smart" initiatives is defined by the innovative use of state-of-art technology systems. 
The literature, at large, identifies urbanization as the key factor that has fostered the emergence and growth of the smart-city concept. The prediction is for 26 smart cities to emerge by 2025, predominantly from North America and Europe [9]. The allocation of resources that forms the basis for cities to become smarter in orientation is foundational to the concept. Underlying the allocation of resources is the very need of developing smart solutions to emerging problems in many of the cities around the world where urbanization has resulted in the growth of more populous cities. Clearly, population increase in cities has led to the emergence of problems that encompass health, economic, social and environmental conditions.

As a result, administrators have employed mechanisms for effective governance with the objective of solving specific problems. Snow et al. [1] use "Smart Aarhus, the smart-city initiative of Aarhus, Denmark" (p. 93) as a case to emphasize how such problems are being addressed. Technical and social problems that Aarhus had to deal with were addressed by "integrating and synchronizing its systems for water, transportation, energy, healthcare, waste removal/recycling, and so on". The authors further point out that the goals and objectives were accomplished by using collaboration as the platform on which execution of the plan was achieved.

Smart cities have specific characteristics that form a basis for the accomplishment of objectives. These characteristics have been identified in the literature to include: efficient information and communications technology (ICT), co-creative platforms to engage stakeholders from idea generation to product solution stages, effective use of data generated through interfaces with key stakeholders, including big data availability using state-of-art systems. In this regard, the use of open data is an emerging concept in the identification and provision of smart solutions to key stakeholders [10].

The smart city concept emphasizes on human capital and infrastructure with information management at its core [11]. Smart solutions are a function of how key skills of employees are used in the delivery of outcomes. Problem solving needs to be at the heart of such an approach achieved through an integration of systems encompassing public and private sector entities. Inter-organizational collaborative platforms form an integral part of such an approach founded on an architecture that leads to public-private partnerships. At the center of this is the essence of providing key services (and solutions) with the overall objective of benefiting society and the public at large that includes welfare oriented objectives. This approach is consistent with the latest trend of urbanization which focuses on human capital [12].

Smart cities can achieve key objectives using resources that are dependent on the deployment of ICT and governance mechanisms founded on transparency, customer centricity and efficiency [12]. Moreover, a major characteristic of such cities is their citizens who engage at a high level and use networks that enable better communication and coordination. The pillars of a smart city are essentially people, technology and processes in how they connect with various sectors including healthcare, education, transportation, telecom, tourism, utilities, public safety and buildings. Even control systems have web-enabled mechanisms, which provide an integrated approach to managing outcomes. In essence, the characteristics of a smart city could be summarized to include six elements: Smart Mobility, Smart Government, Smart Economy, Smart People, Smart Living and Smart Environment $[13,14]$.

A ranking of smart cities in 2015 suggests that Barcelona was identified as the top smart city in the world as it consistently ranked "above average" on all attributes related to the smart city concept, even though cities such as New York and Singapore ranked above Barcelona on certain attributes [15]. However, the ranking in 2016 saw Singapore, which was in fifth position the previous year, rise to the top position ahead of Barcelona [16]. The attributes related to technology, buildings, utilities, transportation and road infrastructure, and the smart city itself (originally identified by Sorrell [17]) were the characteristics that were essentially used to define the "smart city" concept. The cities that ranked high on the list were ahead in terms of the efficient use of integrated systems and processes to optimize on energy consumption while reducing waste and congestion. The use of technology was 
identified as an integral component of the system characteristics. Such systems are used across various sectors ranging from healthcare and transportation to utilities and tourism.

\subsection{Smart Tourism and Smart Tourism Destinations}

Smart tourism and its emergence is directly related to the smart city concept. Sustainability is at the crux of the growth of smart tourism and more destinations are now prioritizing it as a strategic objective in the tourism planning process. A greater emphasis is placed on planning and implementation of sustainable measures through smart solutions involving various entities including government, educational institutions and other such stakeholders that encompass private- and public-sector institutions. Such initiatives have impacted infrastructure development both from broader (across various sectors) and narrower perspectives, the latter being specifically related to tourism. This may be seen in the case of specific developmental projects encompassing smart airports, smart hotels and smart transportation, which includes airways, waterways and surface transportation systems.

Despite that, the emergence of smart cities globally has had an influence on the tourism sector. A key ingredient that makes destinations smart is the use of technology. ICT has made a difference in this regard which provides users seamless solutions and integrated access with a focus on improving tourist experiences; increasing efficiency; improving process automation $[14,18]$, all of which are integral to sustainable tourism destinations.

The overall objective of smart tourism is to provide an interface between the visitor and the destination for a responsive orientation towards solving specific needs. A smart tourism destination is characterized by a high level of innovation and facilitation using higher order technology and interfaces [14,18]. In particular, such destinations use "advanced technologies and open, multipolar, integrated and shared processes" with the aim of improving the quality of life of residents and tourists alike [19] (p. 1408). Optimization of resources is integral to the functioning of systems in smart tourism destinations which connects such a concept to sustainability.

Zhang, Li and Liu [20] identified smart tourism destinations to comprise of three specific components such as cloud services, the Internet of Things (IoT) and End-user Internet Service System. A key characteristic of cloud services is that it provides web-browser based access to a variety of technological tools including applications, software and data [21]. The IoT provides smart destinations with support regarding information management/analysis and sophistication as it relates to automation and control [21]. The end-user service systems support users with tools (equipment) and applications to be able to access the services related to tourism. These include applications that are oriented towards serving tourists which enable access to products and support services including the use of payment system and interfaces; telecommunication devices and interfaces; wireless connections that include hotspots and other such services; and the like.

Koo et al. [22] identified smart tourism destinations to be effective in the use of platforms for creating unique experiences for tourists and visitors. Such experiences are based on an effective transformation of user data into solutions that relate to specific needs. Koo et al. [22] further point out that collective intelligence is at the crux of system interfaces and applications that underlie technological platforms, which are instrumental in the creation of user experiences. Similarly, Sigala and Marinidis [23] identified system advancements (such as Web 2.0) founded on a knowledge management perspective as integral in managing the efficacy of processes that are based on transformations of stakeholders' tacit knowledge to explicit knowledge. This enables such smart systems to effectively use (including process, store, recall and share data and information) knowledge and to configure solutions, and address situational needs of the users. Therefore, it may be argued that collaborative systems are effective as such interfaces provide a basis for better communication, coordination and reciprocity $[19,23]$.

In a nutshell, key smart tourism destination characteristics include digitization of systems, processes and services; a higher level of interface between the tourist and the destination, which takes into account the local community and government among other sectors; a higher level of engagement 
of local residence in the provision of the products/services; a higher level of data generation and use through integrated smart systems; and above all, a better orientation towards managing tourist experiences [14,24]. Creating and managing tourist experiences in essence is one of the main goals of smart tourism systems [22]. This is possible when, for instance, different tourists interact with a single destination product leading to heterogeneous individualized unique experiences derived from the same product or attraction [25].

\subsection{Comparing Conceptual Frameworks on Smart Cities and Smart Tourism}

The smart city and smart tourism concepts are closely related phenomena mainly due to their common foundational elements. However, a major difference between the two is that smart cities serve their residents while smart tourism is mainly oriented towards visitors/tourists. In essence, smart cities and smart tourism share infrastructure as well as facilities while providing solutions to residents and tourists. However, the literature has delved into them separately and the body of knowledge has evolved into two separate subsets of the "Smart" phenomenon. Even though the two ideas have been examined utilizing separate focal points, common components should be comprehended in light of a theoretical structure. For this reason, we review previous studies first to understand the underpinnings and the progress made in this context, both generically and contextually, i.e., as they relate to Dubai.

Extant research has begun to conceptualize smart cities as an ecosystem, which is comprised of a network of complex and interdependent communities of interacting organisms and their environments [26]. Accordingly, smart cities are comprised of interdependent resources that interactactively provide solutions to residents which address convenience and efficiency aspects of their needs. That being said, the smart city concept has been considered from multifarious points of view in the literature. The plethora of models in the literature address different contextual and situational factors need to be examined in this study before gaps could be identified.

For instance, Anthopulos [27] categorized smart cities into five levels: natural environment, hard infrastructure-non ICT-based, hard infrastructure-ICT-based, services and soft infrastructure, and people. As per Anthopoulos [27], Level 1 contains the natural environment resources, encompasses all environmental attributes such as lakes, forests, rivers, etc.; Level 2 contains all non-ICT related features that are man-made through human intervention, such as infrastructural resources including schools, parks, bridges, buildings, etc.; Level 3 is about hardware-based ICT systems that include supercomputers, data systems and networks, severs, etc.; Level 4 is about services that are defined under smart city services; and Level 5 entails people living in a city including applications, software, databases, and data.

Naphade et al. [28] proposed an alternative model with seven components: government services, transportation, energy and water, healthcare, education, public safety, and other core ICT systems. Further, Glebova et al. [29] conceptualized the smart city with 5 dimensions: intellectual transport systems, public security, energy consumption management and control, environmental protection and ICT. Alternately, Bellini et al. [30] suggested the model based on a data-oriented IT perspective: data sources, administration, street-guide, point-of-interest, local public transport, sensors, temporal, and metadata. Using a holistic perspective, Anthopoulos et al. [31], in a recent meta-analysis (covering 48 publications screened from 4800 articles published between 1997 and 2016) classified the conceptual models into six categories: facilities (e.g., energy, water, IoT, etc.), services (e.g., health, education, etc.), governance, planning and management, architecture, data and people.

In summary, these models have commonalities and differences but largely, the commonalities predominate the differences. Smart infrastructure is integral to all the models encompassing health, transportation, public security, governance, utilities, and data management. Even though many scholars have emphasized that ICT does not necessarily define the "Smart" orientation of cities, the ICT platform is the main characteristic common to most conceptual frameworks and is integral to the successful implementation of the smart city concept. 
From the smart tourism context, different conceptual frameworks have been proposed. For instance, Koo et al. [32] explained the smart tourism architecture as comprising of six layers: IT infrastructure for the integration of networks, sensors, chip, and IoT; data aggregator for the integration of heterogeneous data; platform such as apps, cloud, and open API; policy representing structure, procedure, process, and governance; citizen, who is the driver of innovation as well as consumers of cultural and entertainment activities as a member in the community and economy; lastly, traveler, who is the ultimate consumer of smart tourism. Holistically, Koo et al. [32] framework is an extension of the existing frameworks on smart cities. The first-five layers share identical features with those of smart cities. Likewise, Gretzel et al. [33] identified the main components of smart tourism to comprise of three layers including smart experience, smart business ecosystems, and smart destination. In addition to the three layers, a fourth component of data was added which includes collection, exchange, and processing.

In the same vein, Boe et al. [34] exploratory research framework suggested that the competitive smart tourism destination should have two foundational components: the first component comprising leadership, innovation, and social capital supported by human capital as the fundamental constructs for smartness; and the second component comprising technology applications and ICTs as the enablers supporting the core constructs of smart destinations.

It could be deduced from Koo et al. [32] and Boe et al. [34] that infrastructure is integral to the development of the smart city concept. Common characteristics that cut across their frameworks include policy, human capital, innovation and IT infrastructure, natural resources and environments. More importantly, the role of IT was identified as a key element to determine the competitiveness of smart cities as well as smart tourism. Using the foregoing implication as a precursor, this study used Dubai as a context to analyze the smart city concept and the orientation towards smart tourism.

\section{The Dubai Smart City}

\subsection{Current Status}

Dubai officially launched "Smart Dubai", its smart city concept, in March 2014. Historically, the city had implemented other major projects directly or indirectly related to the "smart" concept before the launch of Smart Dubai. In 1999, the ICT Strategy of Dubai was initiated, immediately following which the e-government agenda was launched in 2000. Table 1 shows the major milestones of Dubai Smart City.

Table 1. Milestones of Smart Dubai.

\begin{tabular}{ll}
\hline Year & \multicolumn{1}{c}{ Events } \\
\hline 1999 & Dubai ICT Strategy was planned. \\
\hline 2000 & Dubai e-Government Initiative was announced. \\
\hline 2009 & Dubai e-Government Department was open. \\
\hline 2013 & $\begin{array}{l}\text { Smart Dubai Higher Committee was formed. } \\
\text { Higher Committee for the implementation of Dubai } \\
\text { Smart City was formed. }\end{array}$ \\
\hline 2014 & $\begin{array}{l}\text { Smart Dubai Executive Committee was formed. } \\
\text { Open Data Committee was formed. }\end{array}$ \\
\hline 2015 & $\begin{array}{l}\text { Dubai Data Law was announced. } \\
\text { Smart Dubai Office was open. }\end{array}$ \\
\hline
\end{tabular}

While Dubai began to gain international recognition as one of the major cities of the MENA region, major infrastructure that includes tourist attractions and facilities, such as Burj Khalifa and the Dubai Metro, were successfully launched, which in turn significantly enhanced Dubai's profile as a smart city and a smart tourism destination $[35,36]$. At the same time, by virtue of UAE's steady 
investment in IT infrastructure, out of a total population of 9.58 million in 2015, 8.81 million became active Internet users (91.8\%), the second highest ratio after Canada (93\%). Among these Internet users, 7.27 million are mobile Internet users (75.9\%). Notably, 5.4 million active social accounts exist [37], out of which 4.6 million (85.2\%) are mobile accounts. According to the World Economic Forum report [38,39], UAE ranked 1st in the area of "Importance of ICT to Government Vision" and the 2nd in "Government Success in ICT Promotion". All these facts, including the milestones identified in Table 1, reflect that Dubai has initiated and successfully implemented smart projects over the past few years. That being said, it is essential to delve into some of the underlying factors, which are detailed in the following subsections.

\subsubsection{Six Dimensions of Smart Dubai}

The ultimate goal of Smart Dubai is "to become the happiest city on earth", for citizens, residents and/or visitors alike $[40,41]$. The vision is not just to become the smartest in terms of technology adoption, but to be one of the happiest places to live and work in the world. At the same time, it aims to be the world's best-connected cities. For this purpose, the city has pioneered to adopt the latest technology as the platform to realize the "Happiness" vision, which will allow citizens and residents to raise their living standards and their quality of life. In regards to Dubai's aim to become the smartest city in the world, technology has been adopted across four pillars and six specific dimensions [40-42]. They include:

- Efficient: To become a city where resources are used in an optimized manner.

- Seamless: To integrate day-to-day life services across the city and its inhabitants.

- Safe: To carefully anticipate risks and protect people and information.

- Impactful: To make a difference through an enriched life and fulfilling business experiences.

The above four pillars span six dimensions of Smart Dubai, as follow:

- Economy: Where intelligent and innovative economic conditions and tools are provided to fuel entrepreneurship and competitiveness.

- Governance: Where transparent government services exist for both public and private sectors.

- Environment: Where asset management is used intelligently to minimize pollution and resource wastes. Examples are smart grid and buildings integration, smart water irrigation, smart sewage water, smart storm water management, and smart waste management.

- Living: Where an exceptional quality of life is present as it relates to education, healthcare, and cultural lifestyle. Examples are smart buildings, smart home, building and facility management, eHealth, and total healthcare stations.

- Mobility: Where the transport of people, things, and ideas is seamless and efficient. Examples are infrastructure for smart roads, bridges and tunnels, Intelligent Transport System (ITS), and smart traffic and parking management.

- People: Where people welcome a culture of continual learning, involvement, and innovations. Examples are smart education and smart security.

The six dimensions of Smart Dubai entail hundreds of initiatives and ten times as many government services in the areas of infrastructure, urban planning, transport, electricity, communications and economic services. They are being implemented to provide smart services to citizens. To implement these plans and projects effectively, the city has identified and put into place four different layers [41]. (1) The application layer is responsible for the audiences who make use of dashboards and related applications within a particular ecosystem. (2) The service enablement layer is about analyzing private and public data as well as setting up the necessary governance procedures. (3) The data orchestration layer focuses on the inflow of secure and accessible data at all times. (4) The infrastructure layer emphasizes the generation and management of citywide data 
encompassing platforms such as ICT and the IoT. These layers work in conjunction to form an integral part of the dimensions and pillars entailing the Dubai Smart City.

Of the six dimensions, mobility, living, and environment dimensions are technology-intensive areas where major projects have been implemented over the past several years. In the case of mobility dimension, the Road Transportation Authority (RTA) of Dubai has made significant progress in building smart systems, which include smart parking, smart taxi, smart Salik (toll system), smart drive and other such infrastructure that make use of technology. The adaptation of smart technology will allow Dubai to achieve its overarching goal of focusing on people's happiness by fostering a two-way communication between public- and private-sector entities and their customers. For instance, the RTA in itself has six different mobile applications that connect all its users on a unified platform [42,43]. Apart from these applications to users, there are other mobile applications for RTA drivers and vehicles, and RTA Corporate Services. These applications offer basic tracking and paying services, which also serve as a means of creating awareness about RTA's offerings. These applications have been recently integrated with the Happiness Meter (see Section 3.1.2) for tracking and analyzing purposes.

In regards to the living dimension, healthcare, education and utilities are being developed with the objective of providing smart solutions [44]. Healthcare solutions are aimed at longevity while getting citizens to lead healthier and happier lives. Healthcare analytics are the order of the day given the scale of data and their use, which are coupled with remote services such as telemedicine and smart healthcare systems that enable a smooth interface between patients and hospitals. These integrated systems assist in the provision of superior customer oriented services.

In the same vein, education is delivered using smart solutions through student-centric services that can be accessed through on-line interfaces [45]. These solutions are developed using a teacher-friendly system that improves efficiency and effectiveness in the delivery of programs. On-line solutions and interfaces that include technological platforms have resulted in better teacher and student experiences. User-centric educational services have in fact created a platform where students can co-create specific programs that meet their idiosyncratic requirements.

In the environment dimension, smart energy is the main focus of state-of-the-art systems that provide a basis to manage power, which includes smart meter and smart grids. Water management that includes water quality, availability and utilization of water and the management of infrastructure is an important component of the provision of utility-based services. These solutions are oriented towards "green" outcomes where the focus is on efficiency and effectiveness in the use of energy systems and in the delivery of products and services. A major focus of such initiatives is in the development of green buildings that have a clear link with the smart solutions identified above.

Reducing carbon emissions are at the crux of actions that relate to environment and sustainability. Dubai has made significant progress in this regard reducing emissions leading to significant cost savings across various sectors. The objective by 2020 is to reduce emissions by $30 \%$ [46]. Moreover, emphasis is being placed on air quality, water quality, including marine and ground water quality, and soil quality, which collectively lead to an improvement of the environment [44]. Even waste management has had a smarter outlook in terms of how landfills are being managed.

Even though ICT is not included in the six dimensions, it is an integral component of Dubai's infrastructure. For instance, Dubai is growing at a rapid pace to meet global standards of information technology related infrastructure encompassing broadband and Wi-Fi connectivity that are identified as the building blocks of smart city development. This is seen with the advent of telecom companies such as Du and Etisalat that have high-speed internet connectivity based solutions for its customers in the UAE while providing hotspots for instant connections within the country. Communications technology has advanced to a level where the hotspots are provided through "Tree Technology" in Dubai which is a cultural extension of the use of the date palm as detailed in the following quotation: 
"Since the days of the Bedouins, the date palm has been a constant source of refuge and nourishment our Emirate's desert climate. Enter the modern iteration of the date palm: the Wi-Fi-emitting, phone-charging Smart Palm. Standing at six meters tall, the impressive-looking artificial trees use solar power (which is, of course, plentiful in Dubai) to provide free Wi-Fi hotspots, charging ports for phones and other gadgets and information such as weather and news displayed on the 'trunk'” [47]

The above is in tandem with the developments seen in major smart cities where such infrastructural requirements were addressed [12].

In terms of technology adoption, Dubai aims to do a global pilot test in order to implement new technology to sustain its Happiness vision as well as to remain competitive. Table 2 shows the IT projects that Dubai has started recently that are directly connected to its mission and vision.

Table 2. New Technology Projects in Dubai.

\begin{tabular}{cl}
\hline Name & \multicolumn{1}{c}{ Content } \\
\hline Uber Airplane Taxi & $\begin{array}{l}\text { Uber, which is a partner of the Dubai government, plans to introduce flights } \\
\text { during EXPO 2020. Airplane Taxi is planned to become a fundamental part } \\
\text { of Dubai's transport infrastructure in the near future [48]. }\end{array}$ \\
\hline Dubai Loop Train & $\begin{array}{l}\text { The Hyperloop is planned to be operational by Expo } 2020 \text { between Dubai } \\
\text { and Abu Dhabi by 2020, EXPO 2020, which will take only 12 min [49]. }\end{array}$ \\
\hline Smart Tunnel at Airport Immigration & $\begin{array}{l}\text { The Dubai airport plans the Smart Tunnel project, which allows passenger } \\
\text { to finish the entry procedure within 15 s simply walking through the tunnel } \\
\text { without stamping the passport or any other human intervention [50]. }\end{array}$ \\
\hline \multirow{3}{*}{ Dubai Blockchain Strategy } & $\begin{array}{l}\text { Dubai will be the first government using the blockchain technology. It will } \\
\text { be applied in fin-tech and banking and real estate to increase the efficiency } \\
\text { of government's operations [51]. }\end{array}$ \\
\hline Etisalat Mobile & $\begin{array}{l}\text { Etisalat, one of two telecommunication corporations in Dubai, introduced } \\
\text { the Near Field Communications (NFC) to allow phones to access the metro } \\
\text { and buses including payment. In 2018, the number of NFC mobile payment } \\
\text { users is projected to 166 million [52]. }\end{array}$ \\
\hline $\begin{array}{l}\text { UAE's Ministry of Health launches mobile health systems where patients } \\
\text { can be monitored and treated using technology. Obesity, diabetes, } \\
\text { cardiovascular and respiratory diseases are major areas to be treated [53]. }\end{array}$ \\
\hline
\end{tabular}

\subsubsection{Happiness Meter Index and Smart Dubai Index}

The measurement and development of Key Performance Indexes (KPIs) are evaluative components of smart cities that include monitoring and feedback systems related to IT infrastructure. It should be noted that the types of indexes and measurement methods are diverse depending on the purpose of use. Anthopoulos et al. [31] classified the measurement of smart city into five classes: smart city progress measurement, smart city monitoring, city capacity, sustainability, and policy. Among these five, the first two classes are directly related to the progress and development of smart city. For instance, Caragliu et al. [54] used 250 indicators to measure several domains such as demography, social aspects, economic aspects, civic involvement, etc., Lee at al. [55] developed indexes, called Smart Service Assessment Indexes, Smart Device Assessment Indexes, and Technology Assessment Indexes. Malek [56] developed the Informative Global Community Development Index (IGC) to monitor the Smart Cities initiative. In this regard, the Smart Dubai initiative has developed two types of indexes: Happiness Meter Index and Smart Dubai Index.

Dubai is highly multicultural with more than 180 nationalities, a majority of them being expatriates [57]. Accordingly, the Happiness concept, which is an integral part of the Smart Dubai vision, is not just oriented towards productivity, efficiency, livability and sustainability. The overarching objective of the smart city initiative is fueled by the Happiness concept where systems, solutions and services are defined using this initiative, including major objectives and related targets. 
The Happiness Meter Index measures the level of satisfaction at the highest level. It is a city-wide happiness meter launched across all government entities, with online and offline interfaces [58]. Measurement is processed through smart (online) devices installed at the headquarters of government organizations and connected to the central database that monitors performance on a real-time basis. Timely system generated reports are sent to decision makers which effectively form the basis of control systems. Through this process, areas and functions that meet or exceed happiness related performance objectives, as well as those that do not, are identified. For instance, in 2016 alone, one million interactions with the public were gathered across 31 government entities which formed the basis to monitor and track public services and outcomes. Currently, the happiness portal measures various services to residents as well as visitors (see Figure 1).

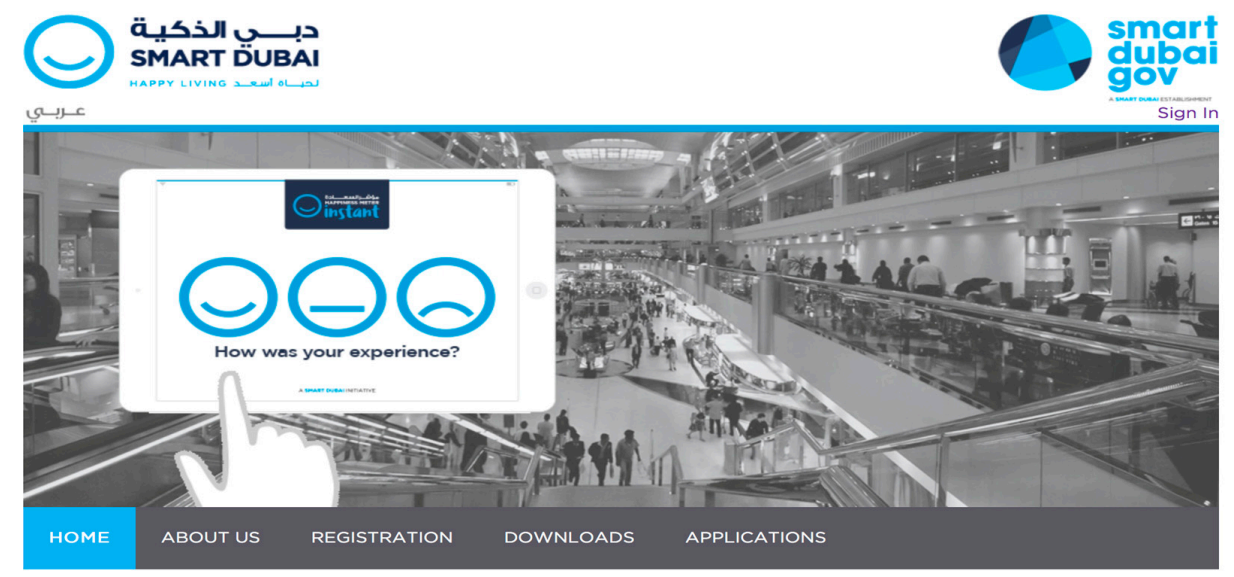

Figure 1. Dubai Happiness Meter Portal Site [58]

Another measurement indicator is the Smart Dubai Index. This index was developed with the International Telecommunication Union (ITU) after pilot projects were run over a two-year period. It is comprised of six components that essentially link to the six dimensions of Smart Dubai, including a set of KPIs to measure the progress of smart city development (see Figure 2).

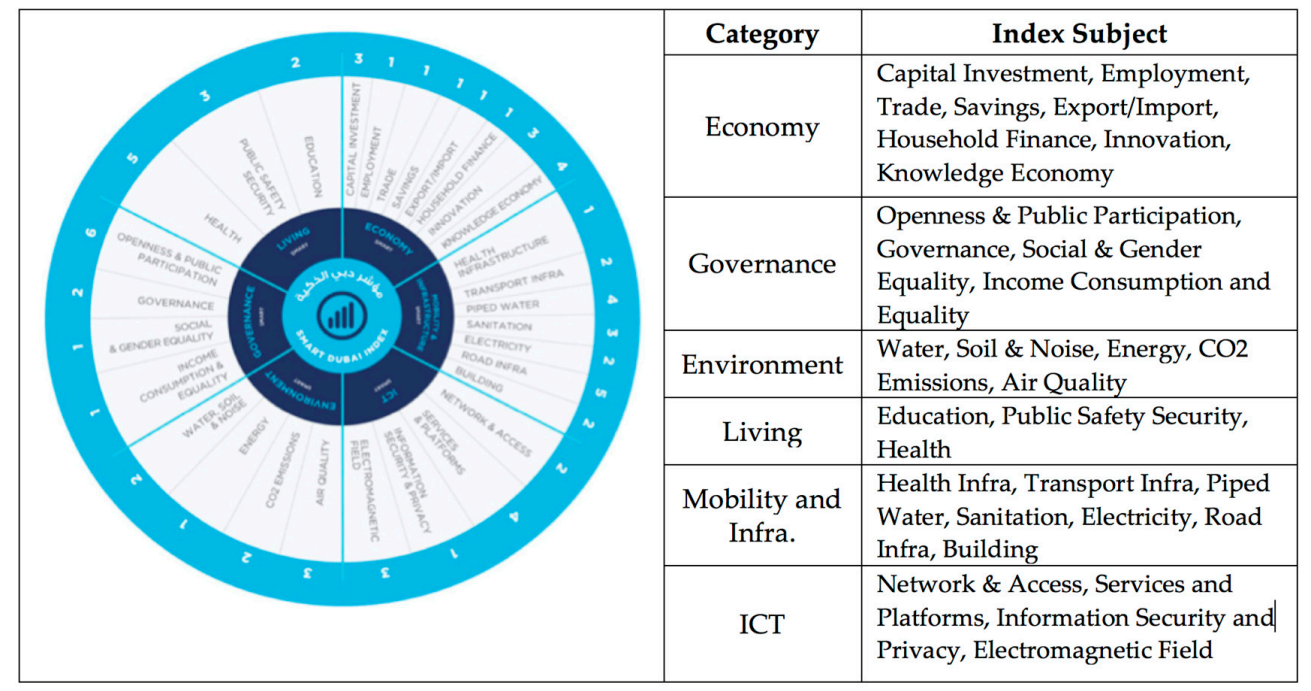

Figure 2. Smart Dubai Index [41]. 


\subsection{Dubai's Information Infrastructure: Dubai Data Law}

Recent trends suggest that many data are being generated daily which provides opportunities for organizations and societies to become smarter and more connected. Cities all over the world are making a significant move towards digitalization. In alignment with this trend, both public- and private-sector organizations are becoming more aware of the value of data and data management systems in transforming to a smart organization at the micro level, and to a smart, safe and seamless city at the macro level.

Although Dubai has achieved remarkable technological advancements, the city had historically suffered from some setbacks that stalled its smart city initiative. For instance, UAE is ranked 52nd among 86 countries on the Open Data Barometer, which measures the efforts made by governments to apply better governance and processes related to data development [59]. Major barriers related to data exploitation included limited technological capacity and human capital. As a result, the city had enormous amounts of data that were unstructured, unorganized, and with very poor or barely any linkages. Because of this, the Smart Dubai initiative was not exploited to realize its potential due to a lack of standards and frameworks to ensure its success.

In 2014, a cross-governmental committee, namely "Open Data Committee" (ODC), was formed to address the need to develop the city's technological infrastructure [41]. ODC consists of eight organizations: Dubai Smart Government Department, Department of Economic Development, Dubai Police, Dubai Roads and Transport Authority (RTA), Dubai Municipality, Department of Tourism and Commerce Marketing, Telecommunications Regulatory Authority, and Dubai Centre for E-Security. The proposal aimed to create a balance between maintaining the privacy of data across the city and making them available to those organizations that could make use of them. Part of this necessitated the introduction of cross-city data sharing techniques. Because of the work culture prevalent within organizations in the past, many organizations were reluctant at first to take part in what they saw as a major limitation to their competitiveness. Due to the predominant conservative nature of the city's culture, many organizations found it difficult to share data until they realized the value inherent within such initiatives. As a result, the committee focused greatly on converting the mindset of key players from being conservative to being less traditional. It was critical to communicate the message that data can be better utilized as a public good rather than as a private resource.

To facilitate the process of data-sharing and classification, the committee introduced the concept of "Dubai Data", which encompasses all data that have a governmental nature and could be related to the culture and societal life of Dubai. The intent is that the ownership of data that are of use to the city in any aspect, such as its economy, culture, education, business or people, belong to the city itself and not to a particular entity.

The Dubai Data Law finally came into being in October 2015 and Dubai Data, championed by the Dubai Data Establishment (DDE), is to share 10 percent of public sector data by 2021 along with some private sector datasets [41]. According the Dubai Data Law, all data that are not personal, sensitive or confidential, are open for public use by default. No approval process is required for such data. The main objective of this law is to ensure the availability of all data that promote better decision-making. Along with a clear definition of this law, guidelines as to what responsibilities and duties fall upon each individual were provided. It is important to state that the law not only governs Dubai's public-sector firms, but also other organizations within the country that may own valuable information about the city.

The Dubai Data initiative underpins the Smart Dubai strategy and its relevant major components that facilitate the efficient exchange of data and information, and streamlines the seamless connectivity for the public and private sectors. Dubai Data initiative follows four principles: open data, shared data, big data, and rich data [60].

- Open data: Data published by the government or private sector to be used or exchanged with individuals or third parities openly. 
- Shared data: Data to be available for sharing and re-use among entities.

- Big data: Large amounts of data to be analyzed to reveal patterns, trends, and associations.

- Rich data: Big data to be further utilized to deeper, often qualitative analyses, and extracting insights.

As a result of open and shared data, government organizations can effectively collaborate with each other as well as with citizens and the private sector. The government hopes to increase engagement and participation of citizens and residents in a manner that will benefit both the private and public sectors. It also allows the private sector to create new businesses, to grow existing ones and to increase overall efficiency. Residents and tourists will be allowed to access more data and services than before. It hopes to make Dubai a knowledge-based economy through innovation and enrichment of knowledge resources. The major objective through this initiative is economic growth, which will also raise the standards of living. The availability and use of data will lead to the tapping of opportunities along with a better system of communication, allowing Dubai to become more efficient and innovative.

It is estimated that, by 2021, open and shared data will add $\$ 2.8$ billion to the economy every year, which is equivalent to US $\$ 1000$ per person and approximately $1 \%$ of Dubai's forecasted GDP in 2021 [61]. The areas to benefit from this initiative include: public administration; transport, storage and communication; wholesale, retail trade, restaurants, and hotels; and real estate.

\section{The Emergence of Dubai as a Smart Tourism Destination}

\subsection{Perception of Dubai as Destination Image: The Result of Data Mining}

In this section, we attempted to measure the destination image of Dubai as it relates to the smart city concept by using the text mining technique. For this purpose, we collected text data through Twitter from 15 March 2017 to 15 April 2017 that essentially represent the traits of Dubai. The data collection and word counts were completed using the R programming language. As the first step, we obtained the access authorization code to collect data from Twitter and then followed the text preprocessing method [62] to collect and extract all related text about Dubai. Specifically, for this procedure, we followed the steps of tokenization, normalization, stemming and stopwords $[63,64]$.

Note that, while collecting data from Twitter, text data were collected from all anonymous users during the aforesaid period without differentiating tourists from residents living in Dubai because it was not possible to distinguish between them using the message as the only source. However, considering that this study investigates smart city as well as smart tourism in Dubai, the aggregation of the two groups would provide a more comprehensive understanding of Dubai's image.

To categorize Dubai's image, we used Aaker's [65] and Ekinci and Hosany's [66] frameworks [67]. Aaker [65] proposed the brand personality scale (BPS), which consists of five dimensions and 42 traits. His framework classifies 42 traits into five dimensions: sincerity, excitement, competence, sophistication, and ruggedness. In tourism, Ekinci and Hosany [66] developed a destination personality scale (DPS) to understand the perceived image of tourism destinations and to measure destination image based on Aaker's [65] BPS framework. Ekinici and Hosany [66] found that only 12 traits overlap BPS traits while concluding that the DPS' traits need to be further investigated to conceptualize the diversity associated with destination images.

We collected the 75 traits of words describing Dubai's image. The results are shown in Table 3. While extracting the traits related to Dubai's image, we ensured that as many diverse key words were included as possible that described Dubai. This resulted in 33 more traits than Aaker's BPS. However, the results reveal that only 12 traits (italics-typed item in Table 3) coincide with Aaker's BPS traits and four items (italics-typed and underlined item in Table 3) comprising of 12 traits were found to match that of Ekinici and Hosany's [66] framework [67]. Therefore, we argue that Dubai's destination image may not be expressed in certain terms using Aaker's 42 BPS traits as the only basis, and that the 75 traits extracted from this study are more comprehensive in the conceptualization of the Dubai's destination image. 
Table 3. Results of Text Mining.

\begin{tabular}{|c|c|c|c|c|c|c|c|c|c|c|}
\hline No & Sincerity & Freq & Excitement & Freq & Competence & Freq & Sophistication & Freq & Ruggedness & Freq \\
\hline 1 & hot & 639 & nice & 5569 & great & 5309 & beautiful & 4079 & obstacle & 1559 \\
\hline 2 & cheerful & 417 & happy & 4239 & scale & 1591 & new & 700 & breathless & 650 \\
\hline 3 & safe & 259 & enjoying & 3571 & international & 1068 & relaxing & 507 & fast & 361 \\
\hline 4 & cute & 223 & dessert & 2733 & diverse & 1033 & cuisine & 482 & tough & 217 \\
\hline 5 & clear & 204 & dreaming & 2690 & successful & 896 & splendid & 376 & anxious & 137 \\
\hline 6 & cheap & 186 & cool & 1397 & extraordinary & 871 & luxurious & 164 & dangerous & 84 \\
\hline 7 & long & 167 & daring & 848 & famous & 723 & exotic & 124 & tired & 75 \\
\hline 8 & sincere & 163 & $\overline{\text { exciting }}$ & 658 & expensive & 667 & special & 110 & & \\
\hline 9 & spacious & 123 & shopping & 528 & High & 641 & fantastic & 87 & & \\
\hline 10 & important & 123 & expecting & 519 & confident & 428 & attractive & 69 & & \\
\hline 11 & concrete & 111 & unique & 455 & world best & 296 & modern & 34 & & \\
\hline 12 & traditional & 51 & delicious & 348 & strong & 243 & sexy & 30 & & \\
\hline 13 & real & 46 & interesting & 336 & lasting & 141 & soft & 24 & & \\
\hline 14 & friendly & 32 & marvelous & 335 & world first & 119 & elegant & 22 & & \\
\hline 15 & & & beach & 324 & accurate & 90 & & & & \\
\hline 16 & & & hopeful & 218 & growing & 89 & & & & \\
\hline 17 & & & trendy & 217 & perfect & 81 & & & & \\
\hline 18 & & & impressed & 159 & & & & & & \\
\hline 19 & & & cool & 156 & & & & & & \\
\hline 20 & & & miracle & 153 & & & & & & \\
\hline 21 & & & lovable & 132 & & & & & & \\
\hline 22 & & & spirited & 91 & & & & & & \\
\hline 23 & & & trendy & 82 & & & & & & \\
\hline Total & & 2744 & & 25,758 & & 14,286 & & 6808 & & 3083 \\
\hline
\end{tabular}

Italic typed item: traits overlapped with Aaker's [65] Brand Personality Scale (BPS). Italic typed and underlined item: traits overlapped with Aaker's BPS and Ekinici and Hosany's [66] Destination Personality Scale (DPS).

Following Aaker's five dimensions, it was found that the excitement dimension had the highest frequency $(25,758)$, and competency the second highest $(14,268)$. The lowest frequency relates to the sincerity dimension (see Figure 1). In regards to each individual trait, "nice" is the most frequently used word appearing 5569 times, followed by "great" (5309), "happy" (4239), "beautiful" (4079), and "enjoy" (3571) in terms of frequency (see Figure 3, as well as Figures 4 and 5 for the result by individual trait).

Our results suggest that tourists and residents perceive Dubai as one of the most competitive cities in the region. Dubai has several landmarks such as Burj Al Arab and Burj Khalifa that boasts of being the most luxurious hotel and the tallest building in the world. At the same time, many multinational companies consider Dubai as one of their regional business hubs. In summary, our text mining analysis reveals a positive image of Dubai, which appears to be consistent with recent trends. The fact that the excitement dimension has the highest frequency is associated with this trend.

Furthermore, the text mining analysis reveals that the technology-based smart image is not explicitly associated with Dubai even though the city launched the smart city projects a few years ago. The notion that Dubai does not have the technology-oriented smart image cannot be upheld. This is given that most tourists who visit Dubai are provided with an array of smart solutions that include several services ranging from free Wi-Fi access to diverse mobile applications. Even though our findings related to text mining did not explicitly connect Dubai to the smart concept, one may however interpret that Dubai is "smart" in its orientation as one of the dimensions, namely "competence", was found to be significant. Note that smart solutions and technological developments are an integral part of the "competence" dimension. Accordingly, it could be deduced that the text mining exercise did indirectly reveal that Dubai is perceived as a smart destination. However, this interpretation needs to be further examined because similar studies have not been conducted using other smart cities across the world. 


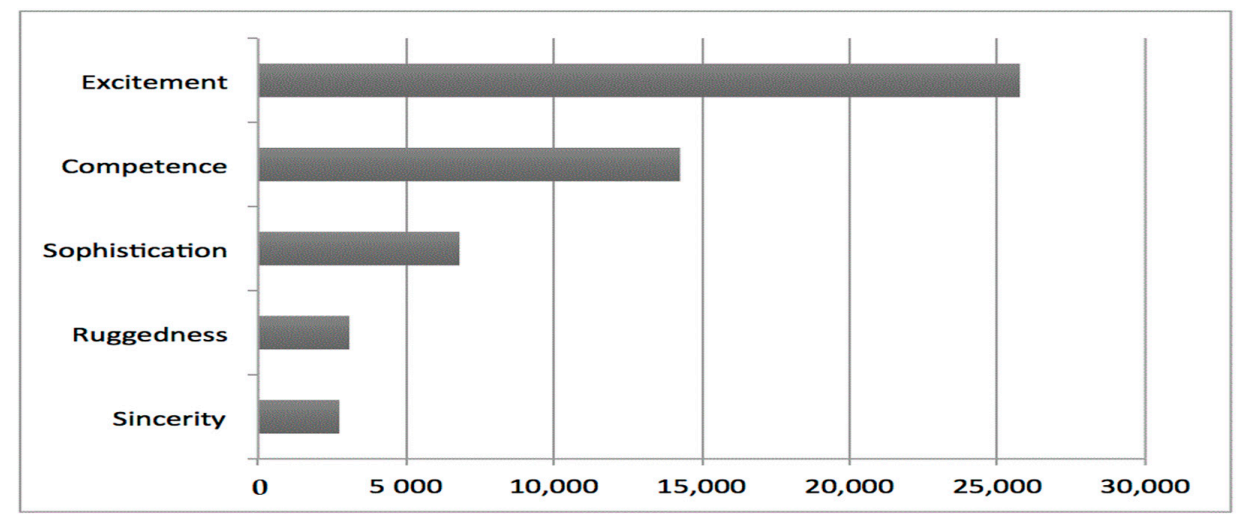

Figure 3. Word Count by Dimension.

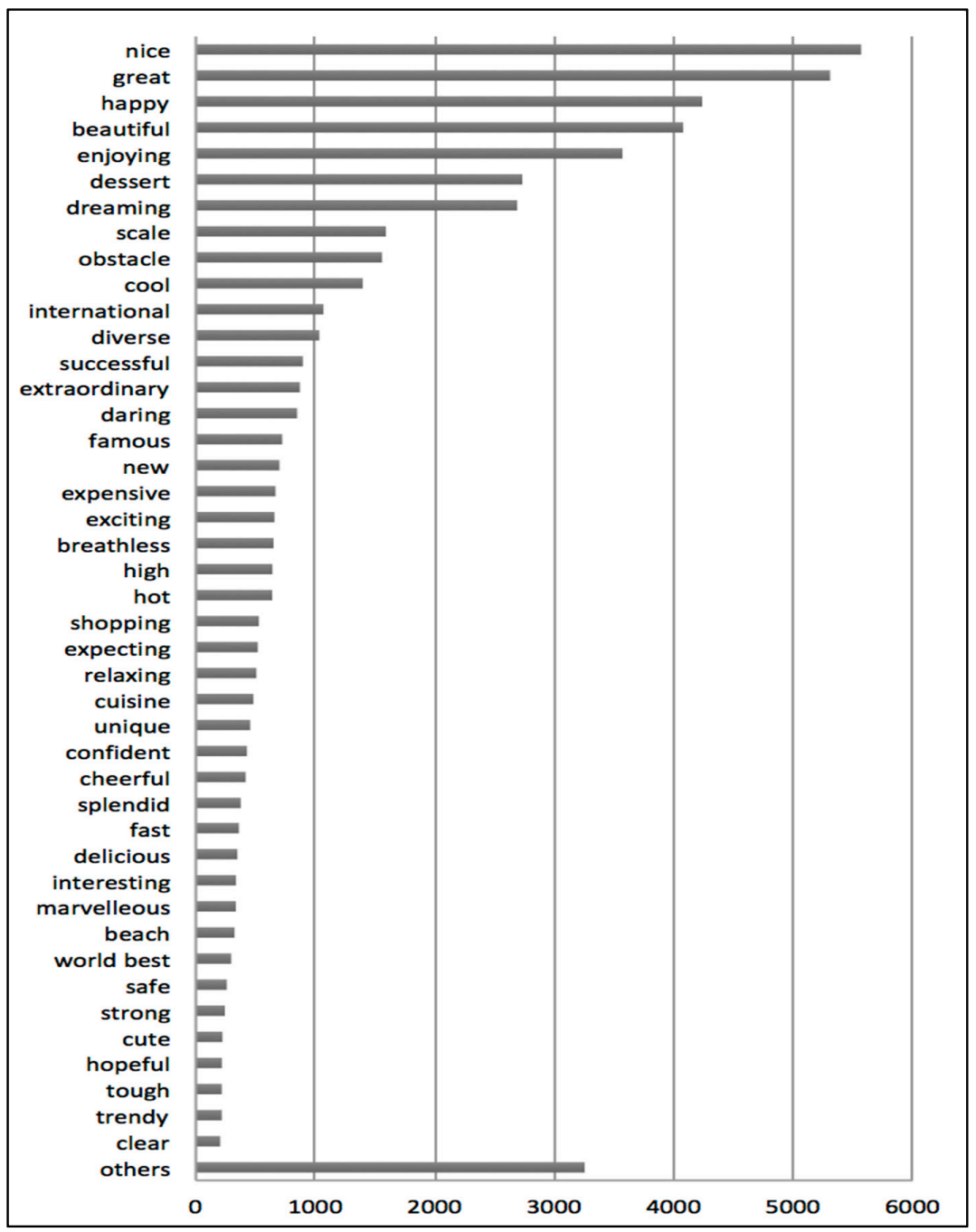

Figure 4. Word Count by Traits. 


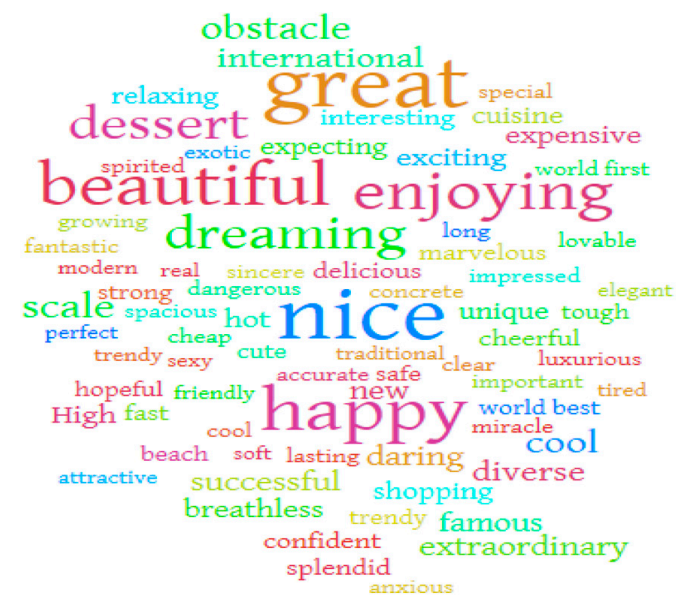

Figure 5. Word Count Result by Word Cloud Method.

\subsection{Dubai as a Smart Tourism Destination}

Dubai has grown in the use of technology-based solutions in managing key tourism products, services and resources in general. These resources include major infrastructural components such as airport, hotels, transportation, and in broader terms, in the configuration of specific products and services that deliver value to tourists. In addition, Dubai has developed diverse mobile applications that not only increase tourists' and residents' happiness, but also help in the development of operations into a seamless and efficient resource base for residents and tourists alike. It should be noted that all these applications are associated with the Smart Dubai initiative related to infrastructure development. Table 4 highlights popular mobile applications that provide smart solutions for residents and tourists.

Table 4. Popular Mobile Applications in Dubai.

\begin{tabular}{cl}
\hline Application & \multicolumn{1}{c}{ Usage } \\
\hline iDubai & $\begin{array}{l}\text { This is the official app for Dubai Municipality. This application includes a map } \\
\text { that lists every point of interest such as offices, clinics, banks, hospitals, mosques, } \\
\text { schools, malls and pharmacies with an accurate location. }\end{array}$ \\
\hline RTA Dubai & $\begin{array}{l}\text { This application provides road and transportation information about metro } \\
\text { station, bus, and even taxi. It is one of the most popular application to residents. } \\
\text { It also lists tourist places, malls, hospitals and petrol stations. }\end{array}$ \\
\hline Dubai Calendar & $\begin{array}{l}\text { This application is the official listing of all events in Dubai about conferences, } \\
\text { concerts, exhibitions, festivals, etc., which is considered as the gateway to exciting } \\
\text { events in Dubai. }\end{array}$ \\
\hline Time Out Dubai & $\begin{array}{l}\text { Time Out Dubai is a popular lifestyle magazine. This application provides } \\
\text { information about the best options for a good night out, music, restaurants, films, } \\
\text { and hotels. }\end{array}$ \\
\hline mParking Dubai & $\begin{array}{l}\text { This app provides a convenient way to pay for parking in Dubai. This application } \\
\text { makes the payment to parking machines easier because the app automatically } \\
\text { composes an SMS for the user and sends it to the RTA. }\end{array}$ \\
\hline Dubai Metro & $\begin{array}{l}\text { An RTA application provides diverse and rich information to users about Dubai } \\
\text { Metro. }\end{array}$ \\
\hline The Dubai Mall & $\begin{array}{l}\text { This application helps to navigate way around the mall using GPS and a 3D map. } \\
\text { Shops, restaurants, and coffee shops are logically categorized. It also reminds } \\
\text { users of their parking location. }\end{array}$ \\
\hline UAE Yellow Pages & $\begin{array}{l}\text { This application helps to gather all the contact information needed on local } \\
\text { businesses in UAE. }\end{array}$ \\
\hline Careem is a local transportation service while Uber is an international company. \\
\hline Career
\end{tabular}


Currently Dubai implements new technology and is considered as one of the most competitive tourism destinations in the world. Tourists in Dubai can explore key solutions including where to go and what to do using NFC (Near Field Communication) tags that are integrated with their individual devices. Cloud computing has contributed largely to the efficient use of information and its sharing. Tourists can connect with systems seamlessly without having to download the application. The RTA's introduction of the tour guide system "Nahaam" has enabled tourists to interact with the system effortlessly and in an efficient way [68].

Smart Airport has been part of Dubai's major development in the tourism area with Smart Gates now allowing tourists to have a better experience at immigration. Integrating airport services with tourism applications have made access to them easier and effective. A new initiative by the Dubai Government allows travelers to use their smart phones as a passport for immigration. "Emirates Smart Wallet" uses the personal data of travelers, including passport information while connecting them with the e-gate services with the objective of easy clearance during emigration [69]. Airport services are now considering (in the initial phase of rollout) smart trolleys, which is an "intelligent baggage trolley" that not only enables passengers to move baggage at the terminal, but also act as a personal guide through interactive, real-time information.

Moreover, the smart airport project with Huawei that uses a customer centric approach to defining airport systems includes a state-of-the-art infrastructure with customer experience at the crux. The plan encompasses "services that cover almost every aspect of the airport, including fight information and airport operations, passenger transportation and baggage services, connectivity and Internet services, video surveillance, enterprise business operations, and maintenance. Key characteristics of the Modular Data Centre Complex include resilience, quick deployment, reliability, energy-conservation, easy maintenance, and cost effectiveness" [70]. This approach to smart cities focuses on tourism with an emphasis on smart transportation. These new developments related to tourism infrastructure are being considered from a smart perspective with 34 new projects being launched in the 2017-2021 phase that ranges from "autonomous drones, self-driving buses and taxis" to "other innovative projects like expansion of pedestrian crossings, roadside sales and information kiosk" [71]. The city has successfully launched 22 projects in the past three years through the RTA of Dubai and the future projects will further enhance the smart orientation towards transportation.

The above developments will make it more convenient for the user to interact through smart interfaces. The smart orientation will enable the use of NFC to put into place the No. 1 smart payment system that will include all public transport modes in Dubai, ranging from metro, buses, water taxis, road taxis governed by the RTA. Such interfaces will make the system seamless and integrative from a user's perspective [47]. Even customer responsiveness is being considered from a smart perspective. If a caller has to wait for customer service because of busy lines, the call will be cut off automatically and the customer will be called back and connected to the service staff when the line becomes free. Such systems will provide timely services with efficiency and productivity at the crux of the service orientation $[69,71,72]$.

The tourist will be in constant touch with smart systems from information kiosks, retail systems, transport systems, and even healthcare systems. According to Visit Dubai, the use of mobile applications would make it convenient for visitors to use a range of services including accessing attractions, restaurants, entertainment and other tourism services [47].

In fact, most of the major shopping malls, including the Dubai Mall, Mall of the Emirates and Dubai Marina Mall, also have their own apps to help visitors find their way around and explore all the shopping and entertainment offerings available. Navigation has become easier with the advent of mobile applications, especially for visitors unfamiliar with the city. The government recently introduced "Makani Dubai" which enables easier navigation and maneuverability through which buildings are identified so that they are easily accessible. As Dubai does not have street addresses, the provision of services as they relate to delivery, particularly emergency services, needs to be managed effectively, which is made possible through technological solutions [47]. 
The above system has its merits in that the visitor is integrated with the information system at large, which is a basis for him/her to access key information and receive assistance as and when the need arises. A key element of the current system is that the user interacts with the system at multiple points for different solutions. These solutions are provided through different system level functional interfaces. This, in our view, uses a micro-level, unidimensional approach to creating stem interfaces with users, which is superficial at best in that the information flow meets a specific need of the incumbent using a single function at a given time. A dynamic, multifunctional interface to solve user needs when such solutions are of the essence is still lacking in the smart tourism system used by Dubai. The needs could be intertwined that cut across multiple functions which would be addressed through a link between the various subsystems. Without this, the visitor would need to connect with each service function separately that would lead to repeated contacts to address a single problem. We develop a framework in the following section, which first delves into the major challenges faced by the current user-system interface. Following this, we propose a smart system to address the challenges.

\section{A Framework to Address Major Challenges}

\subsection{Major Challenges}

The Smart Dubai concept has its pillars as identified previously, and, as such, is able to deliver value to incumbents. Even so, the question that relates to the integration of the tourism subsystem to the overall smart system of the city needs to be addressed if value for all stakeholders are considered from a holistic perspective. For this to materialize, the subsets need to be defined as satellite systems with a direct linkage to other subsets. In other words, a satellite subsystem (e.g., Smart Transportation) directly linked to the Smart Dubai system should also be linked to the other satellite subsystems such as Smart Healthcare, Smart Mobility, Smart Tourism, etc., for the system to respond holistically to the needs of the user. A direct interface between them will lead to superior responsiveness and interventions to meet specific needs of the user. The interlinkages between the multifarious subsystems would create a visitor-friendly, responsible, responsive and dynamic smart tourism system. At present, meeting situational needs as and when they arise and creating experiences that are linked to individual interactions are being considered at a micro-level instead of using a holistic experiential value creation process.

Despite recent developments related to the use of technology, there are improvements that can be made to the existing infrastructure. The current approach to Smart Tourism appears to be piecemeal in that various projects are being initiated without an overall conceptualization and mapping that connects the dots and link them to the system as a whole. A framework is essential that defines and integrates all tourism related projects that come about in the future. In other words, it is imperative for the authorities to define the holistic system while clearly delineating how the various components of the system would be connected through intra-system interfaces. This would be the basis for configuring how the various projects being launched come together in the provision of smart services specifically related to tourism.

Essentially, there is a need to integrate the various components of the Smart Dubai framework (of which Smart Tourism is a subset) which will enable the components to communicate with each other as it relates to the flow of information and the initiation/provision of services to address the requirements of the user. For instance, if a visitor/tourist needs emergency services because of an accident he/she met with or is taken seriously ill while at the destination which requires intervention from local authorities (health services, police assistance, embassy services, etc.), the call for help needs to be accompanied by the triggering off of information flow from the recipient (agent) of the call (first point of contact) to all other relevant parties that need to provide emergency services to address the problem. These services may include emergency transportation services, hospital emergency services, embassy services (for foreign tourists), insurance services, travel agent services (required 
for adjustment of trip schedule), information flow to relatives in the country of origin, and other such services.

A well-integrated dynamic smart systems framework would be able to initiate and deliver services based on how information flows within it without multiple interventions from the source (i.e., the person whose need is being fulfilled). Currently, the incumbent needs to connect with the system on multiple occasions to meet a specific need or address a particular problem. In other words, these multiple contacts with the same system leads to repetitions that could be addressed if the system is able to use a trigger to set off a chain of actions based on a single piece of information received from the source. A framework is thus proposed and explained in more detail in the following sub-section.

\subsection{A Smart Tourism Dynamic Responsive System (STDRS)}

The STDRS framework proposed in Figure 5 uses multiple levels of integration to develop a tourist-specific responsive system. The multiple levels are identified from the various frameworks in the literature that have essentially linked the tourist to the existing systems at the destination, including attractions, facilities (e.g., ground and air transportation, hospitals, telecommunications, etc.), activities, as well as governance and the like. However, as previously iterated in Section 5.1, the existing frameworks in the literature fail to provide a two-way dynamic responsive system that is a solution provider than a mere information source.

A key differentiating element in the case of Dubai is the Happiness vision that is at the crux of all systems related integration. The objective of all interfaces in the Dubai context is to sustain a good quality of life for all users, with Happiness as the driving force. However, this has to be backed by a system that enables the various components to deliver on this vision. If Dubai aims to achieve the Happiness vision, the current system needs to be further developed to integrate the user with it such that the interaction between the two is based on a two-way interface. This would be a basis for the system to use current and historic information to provide real-time solutions.

As explained in Section 5.1, at present, the system is not responsive enough to provide user-specific solutions that are linked to the underlying need. The level of data mining using historic and real-time information is the key to customize and deliver solutions to users on a timely basis. The two-way process would also mean that adaptive criteria are used in the system algorithm than a predetermined set of criteria that essentially works as an information provider.

As stated previously, Dubai's current system uses multiple layers that include the application layer, the service enablement layer, the data orchestration layer, and the infrastructure layer. These layers do not necessarily provide a holistic approach to managing user experiences, which should be linked to the Happiness vision. To address the gaps, as identified in Figure 6, there are multiple levels at which the system operates and the integration of the various levels is the key to establishing a dynamic responsive system, which is not apparent in the current system that Dubai uses. In essence, the system should be founded on the four pillars such that all levels are integrated across the board using the characteristics related to Efficiency, Seamlessness, Safety and Impact. In other words, these characteristics will cut across all levels to deliver customized solutions to users.

The overarching level that defines the STDRS and the interphase with tourists/citizens/residents is the Smart Dubai vision and mission, which, as detailed previously, includes Happiness at the core. This is the driving force in the formulation of STDRS requirements that guides the systems and its interfaces using the characteristics identified through the four pillars.

The next interface is with tourists and citizens/residents that form the physical and virtual linkages, which are access points for the exchange of information and the provision of services. These interfaces need to be defined using user-friendly characteristics in terms of ease of access and use. The design elements need to be looked into for effective STDRS access and usability. 


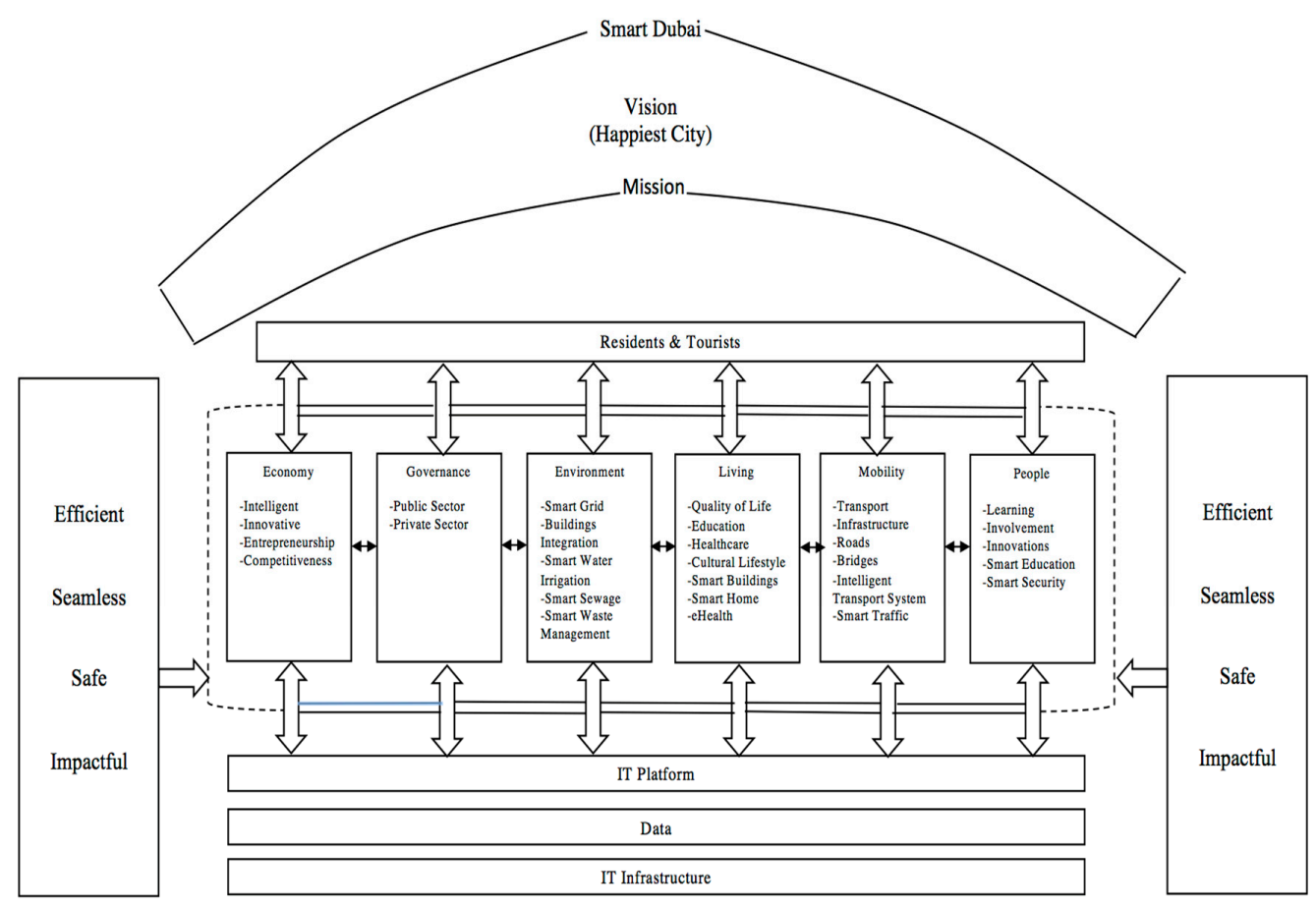

Figure 6. Smart Tourism Dynamic Responsive System (STDRS).

The next level includes the six dimensions that are the subsets identified in the STDRS, which include functional level, applications based interfaces connecting the subsystems related to economy, governance, environment, living, mobility and people. The underlying functions within each subsystem would need to be specifically identified and defined such that intra-functional and inter-dimensional linkages are identified as part of the system architecture.

The functions, as identified previously, include the Economy, which in essence, is demand-supply factors that are directly linked to tourism services, including pricing and other economic variables. They essentially influence the provision of tourism related services. The governance subsystems would encompass services related to travel and tourism, including arrival/departure procedures and requirements, visa and other such tourism access related services, special requirements including permissions that are extraordinary in nature for which government intervention is required.

The Environment dimension and its functionalities are part of the next level, which includes smart subsystems related to grid, building, water, sewage and waste management systems that are integrated to tourism. This will essentially connect the tourist and tourism services to sustainable measures at the macro level.

The Living dimension identifies and connects the STDRS to quality of life as it relates to healthcare, facilities and transportation, among others. Note that tourism related services are an integral part of the system and many of the components of this subset are citizen/resident related functions than tourist related. They include, smart buildings, home, facilities, health and such services. The tourism interface in this case is the health services that needs to be integrated with smart building and facilities services specifically related to tourism.

The Mobility dimension entails services including air, surface and water modalities of transportation. Smart roads, bridges and tunnels, Intelligent Transport System (ITS), and smart traffic and parking management are integrated with tourism to provide tourists with a seamless integration of travel related services. Finally, the People dimension includes subsets related to education, innovation and security which along with the local culture provide the connection to the local environment from a tourism perspective. These subsystems provide the tourist with access and solutions as they relate to culture and people. 
The IT platform is the foundation on which the systems integrate the six dimensions of Smart Dubai to the STDRS. It is a resource provider and the basis for integrating the applications, cloud interfaces, and other such platform functionalities. At this level, all system-related interfaces and solutions need to be executed and managed through the six dimensions of Smart Dubai. This IT platform is integrated to other IT components, which is the basic level of the STDRS. The bottom two layers are the data and the IT infrastructure layers of the current Smart Dubai system.

The framework, as a whole, provides a basis to integrate a tourist to the destination while providing him/her access to the system, not just for information, but for real solutions that, as stated previously, address basic to advanced needs, including extraordinary needs such as emergency services.

\section{Implications and Conclusions}

Smart Dubai has emerged as Dubai's smart city concept, of which Smart Tourism is a part. In this paper, we first reviewed major conceptual underpinnings while identifying how they relate to Smart Dubai and Smart Tourism. Smart Dubai has essentially been developed on vision and mission statements as well as the four pillars and six dimensions. Smart Tourism is a subset of Smart Dubai, and the Happiness vision is at the crux of the Smart Dubai initiative.

In terms of stakeholder perceptions, text mining analysis revealed that dimensions such as excitement and competence are more dominant in how Dubai is generally perceived. We nonetheless deduce "competence" to be related to the smart initiative given that knowledge systems are founded on the competence dimension.

That being stated, there are shortcomings that Dubai would need to address which relate to adaptive criteria that should be an integral part of a dynamic responsive system aimed at meeting the needs of the user. Situational and idiosyncratic needs are user specific and any smart system should be responsive enough to adapt to and provide specific solutions. At present, a piecemeal approach is used where the system largely meets information needs of tourists and visitors.

Our STDRS framework addresses the shortcomings by integrating Dubai's mission and vision to the four pillars that embody the characteristics of the smart system. The six dimensions related to the smart subsystems are the modalities through which functional level needs of users will be met, whereas the IT platform and system network architecture will act as the nerve center that connects the six dimensions of Smart Dubai to the functions of each subsystem.

The STDRS system is unique in that it is based on information flow through an interface between the user and the system. Essentially, this system uses real time information and generates a coordinated real-time response across multiple tourism related functions. Theoretically, this has significance in that no previous smart system based models have used a dynamic responsive system. The systems to date have been situational and unidimensional in the provision of services. The multidimensionality aspect, which is a product of multi-functional interfaces, and a dynamic response system involving their integration, has yet to be explored.

Given the advent of technology, such systems are very much part of the conversation involving the provision of specific solutions to meet user needs. Theoretically, the integration of functions using smart technology is of the essence. Further, trigger points and the initiation of a coordinated response involving one or more functions need to be tested. This would significantly contribute to the literature at large.

Moreover, it would be useful for future studies to delve into the dynamic attributes of adaptive/responsive systems to identify how situational needs and real-time information could be utilized for triggering off a response that meets idiosyncratic needs of the user, including tourists and visitors.

From a practitioner's standpoint, it is imperative, that the viability of the model be tested in a work environment that involves several functional interfaces. However, each component of the model needs to be integrated with the other components through a holistic framework. Practitioners need to develop an approach where functions need to be connected through a system interface. The flow 
of data and the responsiveness of the system through a coordinated network while interpreting and acting on user needs should be the basis for developing the platform architecture. The implementation of this is critical which needs to be based on a resource based approach. Practitioners should simulate how specific tourist needs manifest and how can they be addressed while using the STDRS.

This study has certain limitations. Our research essentially used secondary data to examine the Smart Dubai concept and to identify the gaps without getting into primary modalities of data. Primary data are essential through focus groups and/or personal interviews to identify key issues. Second, data mining analysis was restricted to only English words and contents. If the analysis were conducted with Arabic words, more comprehensive and contextual findings may have resulted. Nonetheless, these limitations do not undermine the findings given the exploratory nature of our study and the strategic importance of a smart system. Our study contributes to the literature in terms of the development and extension of smart city systems for meeting Smart Tourism objectives. Future research should delve into the viability of the STDRS system and its application using confirmatory research methods.

Author Contributions: This research was designed and completed by all four authors. Specifically, M. Sajid Khan contributed to the introduction and literature review sections, including the final review. Mina Woo and Kichan Nam completed the analysis of Dubai smart city and data mining. Prakash K. Chathoth completed the introduction, literature review, discussion and conclusion sections as well as developed the STDRS framework.

Conflicts of Interest: The authors declare no conflict of interest.

\section{References}

1. Snow, C.; Håkonsson, D.; Obel, B. A smart city is a collaborative community: Lessons from smart Aarhus. Calif. Manag. Rev. 2016, 59, 92-108. [CrossRef]

2. Neirotti, P.; De Marco, A.; Cagliano, A.C.; Mangano, G.; Scorrano, F. Current trends in Smart City initiatives: Some stylized facts. Cities 2014, 38, 25-36. [CrossRef]

3. Boes, K.; Buhalis, D.; Inversini, A. Conceptualising smart tourism destination dimensions. In Information and Communication Technologies in Tourism 2015, Proceedings of the International Conference, Lugano, Switzerland, 3-6 February 2015; Springer: Cham, Switzerland, 2015; pp. 391-403.

4. $\quad$ Fjeldstad, Ø.D.; Snow, C.C.; Miles, R.E.; Lettl, C. The architecture of collaboration. Strateg. Manag. J. 2012, 33, 734-750. [CrossRef]

5. Statista. Dubai Tourism-Number of International Overnight Visitors from 2010 to 2016. Available online: http: / / www.statista.com/statistics /284636/visitor-arrivals-in-dubai-from-international-destinations (accessed on 15 October 2017).

6. McCarthy, N. The Cities where Tourist Splash the Most Cash. Forbes, 27 September 2017. Available online: https: / /www.forbes.com/sites/niallmccarthy/2017/09/28/the-cities-where-tourists-splash-themost-cash-infographic/\#73ca3db161c4 (accessed on 17 October 2017).

7. Maeda, C. Tourist Numbers Outpace Dubai Population: New Study. Gulf News, 27 July 2017. Available online: http:/ / gulfnews.com/business/sectors/tourism/tourist-numbers-outpace-dubai-population-newstudy-1.2064961 (accessed on 17 October 2017).

8. Wam. Number of Tourists to Dubai Grows 11\% to $4.57 \mathrm{~m}$ in First 2017. Emirates 24/7, 24 April 2017. Available online: http:/ / www.emirates247.com/business / number-of-tourists-to-dubai-grows-11-to-4-57m-in-firstquarter-2017-2017-04-24-1.651881 (accessed on 20 October 2017).

9. UN Report 2014. Department of Economic and Social Affairs Population, Population Division. Available online: http:/ / www.unpopulation.org (accessed on 29 November 2017).

10. Berrone, P.; Ricart, J.; Carrasco, C. The open kimono: Toward a general framework for open data initiatives in cities. Calif. Manag. Rev. 2016, 59, 39-70. [CrossRef]

11. Bakıcı, T.; Almirall, E.; Wareham, J. A smart city initiative: The case of Barcelona. J. Knowl. Econ. 2013, 4, 135-148. [CrossRef]

12. Storper, M.; Scott, A.J. Rethinking human capital, creativity and urban growth. J. Econ. Geogr. 2009, 9, 147-167. [CrossRef] 
13. Dassani, N.; Nirwan, D.; Hariharan, G. KPMG 2015 Report. Dubai-A New Paradigm for Smart Cities; KPMG International, 2015. Available online: https:/ / assets.kpmg.com/content/dam/kpmg/pdf/2016/04/Dubaia-new-paradigm-for-smart-cities-uae.pdf (accessed on 10 October 2017).

14. Buhalis, D.; Amaranggana, A. Smart tourism destinations. Inf. Commun. Technol. Tour. 2014, 1, 553-564.

15. High, P. The Top Five Smart Cities in the World. Forbes.com. 2015. Available online: https://www.forbes. $\mathrm{com} /$ sites / peterhigh/2015/03/09/the-top-five-smart-cities-in-the-world/ (accessed on 20 October 2017).

16. Internetofthings Institute. The World Smartest Cities. Available online: http://www.ioti.com/smart-cities/ world-s-5-smartest-cities (accessed on 20 October 2017).

17. Sorrell, S. Market Trends \& Competitive Landscape 2016-2021. Juniper Res. 2016.

18. Gretzel, U. Intelligent systems in tourism: A social science perspective. Ann. Tour. Res. 2011, 38, 757-779. [CrossRef]

19. Micera, R.; Pindaro, V.; Splendiani, S.; Chiappa, G.D. SMART Destinations: New Strategies to Manage Tourism Industry. Proceedings of the IFKAD 2013. Available online: http:/ / www.ifkad.org/Proceedings / 2013/papers/session6/084.pdf (accessed on 3 October 2017).

20. Zhang, L.; Li, N.; Liu, M. On the basic concept of smarter tourism and its theoretical system. Tour. Trib. 2012, $27,66-73$.

21. De Esteban Curiel, J.; Delgado Jalón, M.L.; Rodríguez Herráez, B.; Antonovica, A. Smart Tourism Destination in Madrid. In Sustainable Smart Cities; Peris-Ortiz, M., Bennett, D., Pérez-Bustamante Yábar, D., Eds.; Innovation, Technology, and Knowledge Management; Springer: Berlin, Germany, 2017.

22. Koo, C.; Shin, S.; Gretzel, U.; Hunter, W.C.; Chung, N. Conceptualization of Smart Tourism Destination Competitiveness. Asia Pac. J. Inf. Syst. 2016, 26, 561-576.

23. Sigala, M.; Marinidis, D. E-Democracy and Web 2.0: A Framework Enabling DMOS to Engage Stakeholders in Collaborative Destination Management. Tour. Anal. 2012, 17, 105-120. [CrossRef]

24. Wang, D.; Li, X.R.; Li, Y. China's "smart tourism destination" initiative: A taste of the service-dominant logic. J. Destin. Mark. Manag. 2013, 2, 59-61. [CrossRef]

25. Lamsfus, C.; Martín, D.; Alzua-Sorzabal, A.; Torres-Manzanera, E. Smart Tourism Destinations: An Extended Conception of Smart Cities Focusing on Human Mobility. In Information and Communication TechNologies in Tourism; Springer: Berlin, Germany, 2015; pp. 363-375.

26. Gretzel, U.; Werthner, H.; Koo, C.; Lamsfus, C. Conceptual foundations for understanding smart tourism ecosystems. Comput. Hum. Behav. 2015, 50, 558-563. [CrossRef]

27. Anthopoulos, L. Understanding the smart city domain: A literature review. In Transforming City Governments for Successful Smart Cities; Public Administration and Information Technology Series, Vol. 3; Bolivar, M.P., Ed.; Springer Science \& Business Media: New York, NY, USA, 2015.

28. Naphade, M.; Banavar, G.; Harrison, C.; Paraszczak, J.; Morris, R. Smarter cities and their innovation challenges. IEEE Comput. 2011, 44, 32-39. [CrossRef]

29. Glebova, I.S.; Yasnitskaya, Y.S.; Maklakova, N.V. Assessment of cities in Russia according to the concept of "Smart City" in the context of the application of information and communication technologies. Mediterr. J. Soc. Sci. 2014, 5, 55-60. [CrossRef]

30. Bellini, P.; Benigni, M.; Billero, R.; Nesi, P.; Rauch, N. Km4City ontology building vs. data harvesting and cleaning for smart-city services. J. Vis. Lang. Comput. 2014, 26, 827-839. [CrossRef]

31. Anthoroulos, L.; Janssen, M.; Weerakkody, V. A unified smart city model (USCM) for smart city conceptualization and benchmarking. Int. J. Electron. Gov. Res. 2016, 12, 77-93. [CrossRef]

32. Koo, C.; Park, J.; Lee, J. Smart tourism: Traveler, business, and organizational perspectives. Inf. Manag. 2017, 54, 683-686. [CrossRef]

33. Gretzel, U.; Sigala, M.; Xiang, Z.; Koo, C. Smart tourism: Foundations and developments. Electron. Mark. 2015, 25, 179-188. [CrossRef]

34. Boes, K.; Buhalis, D.; Inversini, A. Smart tourism: Ecosystems for tourism destination competitiveness. Int. J. Tour. Cities 2015, 2, 391-403. [CrossRef]

35. Balakrishnan, M. Dubai-A star in the east: A case study in strategic destination branding. J. Place Manag. Dev. 2008, 1, 62-91. [CrossRef]

36. Foggia, G.; Lazzarotti, V. Business implications of local development policies: The case of Dubai and the travel industry. Theor. Empir. Res. Urban Manag. 2013, 8, 78-91. 
37. UAE Internet Social \& Mobile Statistics 2005, Infographics. Available online: http://www. globalmediainsight.com/blog/uae-internet-stats-infographics-2015/ (accessed on 15 October 2017).

38. AME Info. Available online: http://ameinfo.com/finance/archive/uae-ranks-first-mobile-networkcoverage-importance-ict-government-according-wefs-nri/ (accessed on 15 October 2017).

39. Federal Competitiveness and Statistics Authority, Global Information Technology Report by WEF. Available online: http:/ / fcsa.gov.ae/en-us/Pages/Competitiveness/RanksReadMore/Global\%20Information\% 20Technology\%20Report.aspx (accessed on 13 October 2017).

40. Smart Dubai. Available online: http:/ / www.smartdubai.ae (accessed on 20 October 2017).

41. Salem, F. A Smart City for Public Value: Digital Transformation through Agile Governance-The Case of Smart Dubai; Mohammed Bin Rashid School of Government: Dubai, UAE, 2016.

42. 2021 Dubai Plan. Available online: https://www.dubaiplan2021.ae/dubai-plan-2021/ (accessed on 13 October 2017).

43. Roads \& Transport Authority, Government of Dubai. Available online: https://www.rta.ae/wps/portal/ $\mathrm{rta} / \mathrm{ae} / \mathrm{home}$ (accessed on 15 October 2017).

44. Dubaicityguide. Available online: http://www.dubaicityguide.com/m/features/?id=7415\#.Wfa05Ux7HdQ (accessed on 13 October 2017).

45. Smart Dubai. White Paper: A Collaborative Approach to Smart City Transformation. 2015. Available online: http:/ / www.smartdubai.ae/whitepaper/Smart_Dubai_WhitePaper.pdf (accessed on 29 November 2017).

46. Dubai Electricity \& Water Authority, Government of Dubai. Available online: https://www.dewa.gov.ae/en (accessed on 15 October 2017).

47. Visitdubai.com. Available online: https://www.visitdubai.com/en/articles/smart-city (accessed on 19 October 2017).

48. Foutune.com. Available online: http://fortune.com/2017/04/26/uber-dallas-dubai-2020-flying-taxilaunch/ (accessed on 10 October 2017).

49. The Telegraph. Available online: http://www.telegraph.co.uk/technology/2016/11/10/500mphhyperloop-train-will-travel-from-dubai-to-abu-dhabi-in-12/ (accessed on 10 October 2017).

50. Gulf News. Available online: http:/ / gulfnews.com/news/uae/government/smart-tunnels-to-speed-upairport-checks-in-dubai-1.2102412 (accessed on 25 October 2017).

51. Gulf News. Available online: http://gulfnews.com/business/property/dubai-has-world-s-firstgovernment-entity-to-conduct-transactions-through-blockchain-network-1.2101819 (accessed on 10 October 2017).

52. Etisalat. Available online: http://www.etisalat.ae/en/personal/mobile/misc/nfc/etisalat-mobile-nfcoverview.jsp (accessed on 10 October 2017).

53. Emirates 24/7 News. Available online: http:/ / www.emirates247.com/news/emirates/medical-care-onyour-mobiles-as-mhealth-launched-2014-01-28-1.536437 (accessed on 10 October 2017).

54. Caragliu, A.; Del, B.C.; Nijkamp, P. Smart cities in Europe. J. Urban Technol. 2011, 18, 65-82. [CrossRef]

55. Lee, J.H.; Phaal, R.; Lee, S.H. An integrated service-device-technology roadmap for smart city development. Technol. Forecast. Soc. Chang. 2013, 80, 286-306. [CrossRef]

56. Malek, J.A. Informative global community development index of intelligent city. WSEAS Trans. Inf. Sci. Appl. 2010, 7, 112-121.

57. Dubai Statistics Center, Government of Dubai. Available online: https://www.dsc.gov.ae/en-us/Themes/ Pages / Population-and-Vital-Statistics.aspx?Theme=42 (accessed on 10 October 2017).

58. Smart Dubai Government. Available online: https://happinessportal.dubai.ae/en/Pages/default.aspx (accessed 10 October 2017).

59. Davis, T. Open Data Barometer Global Report: Second Edition; The World Wide Web Foundation, 2015; Available online: http:/ / opendatabarometer.org/assets / downloads/Open\%20Data\%20Barometer\%20-\%20Global\% 20Report\%20-\%202nd\%20Edition\%20-\%20PRINT.pdf (accessed on 12 October 2017).

60. Dubaidata. Available online: http:/ / dubaidata.ae (accessed on 12 October 2017).

61. Dubai Data Economic Impact Report, Dubai Data Establishment. 2017. Available online: http://www. smartdubai.ae/pdfs/DDE_A5_brochure_v5.pdf (accessed 12 October 2017).

62. Vijayarani, S.; Ilamathi, M.J.; Nithya, M. Preprocessing techniques for text mining-an overview. Int. J. Comput. Sci. Commun. Netw. 2015, 5, 7-16. 
63. Mathiak, B.; Eckstein, S. Five steps to text mining in biomedical literature. In Proceedings of the Second European Workshop on Data Mining and Text Mining in Bioinformatics, Pisa, Italy, 20-24 September 2004.

64. Xiang, Z.; Schwartz, Z.; Gerdes, J.H. What can big data and text analytics tell us about hotel guest experience and satisfaction? Int. J. Hosp. Manag. 2015, 44, 120-130. [CrossRef]

65. Aaker, J. Dimensions of brand personality. J. Mark. Res. 1997, 43, 347-356. [CrossRef]

66. Ekinci, Y.; Hosany, S. Destination personality: An application of brand personality to tourism destinations. J. Travel Res. 2006, 45, 127-139. [CrossRef]

67. Shin, S.; Yang, S.; Nam, K.; Koo, C. Conceptual foundations of a landmark personality scale based on a destination personality scale: Text mining of online reviews. Inf. Syst. Front. 2017, 19, 743-752. [CrossRef]

68. DubaiMetro. Available online: http://www.dubaimetro.eu/rta-launches-smart-tourist-guide-servicenahaam/ (accessed on 10 October 2017).

69. GulfNews. Available online: http://gulfnews.com/news/uae/emergencies/now-smartphone-is-yourpassport-in-dubai-1.2040149 (accessed on 3 October 2017).

70. Huawei.com. Available online: http://www.huawei.com/ /media/CORPORATE/PDF/case-studies / dubai-airports-en.pdf (accessed on 3 October 2017).

71. GulfNews. Available online: http://gulfnews.com/news/uae/transport/dubai-steps-up-smarttransportation-drive-1.1985559 (accessed on 5 October 2017).

72. GulfNews. Available online: http://gulfnews.com/news/uae/tourism/nol-cards-to-give-access-to-dubaiparks-museums-1.1868310 (accessed on 3 October 2017).

(C) 2017 by the authors. Licensee MDPI, Basel, Switzerland. This article is an open access article distributed under the terms and conditions of the Creative Commons Attribution (CC BY) license (http:/ / creativecommons.org/licenses/by/4.0/). 